\title{
COMÉRCIO AGRÍCOLA: \\ O BRASIL E A OMC
}

Danielle Annoni*

SUMARIO: 1. Introdução. 2. A Agricultura do GATT à OMC. 3. Acesso a Mercados. 4.Subsídios is Exportações. 5. Medidas de Apoio Interno. 6. Acordo Sobre Medidas Sanitáxias e Fitossanitárias. 7. O Porquê da Abertura do Comércio. 8. Conclusão. 9.Bibliografia.

SUMMARY: 1. Introduction. 2. The Agriculture of the GATT to the OMC. 3. Access the Markets. 4. Subsidies to the Exportations. 5. Measures of Internal Support. 6. Agreement On Measures Sanitárias and Fitossanitarias. 7. The Reason of the Opening of the Commerce. 8. Conclusion. 9. Bibliography.

SUMARIO: 1. Introducción. 2. La agricultura del GATT al OMC. 3. Tenga acceso a los mercados. 4. Subsidios a las exportaciones. 5. Medidas de ayuda interna. 6. Acuerdo en las medidas Sanitarias y Fitosanitaulas. 7. La razón de la abertura del comercio. 8. Conclusión. 9. Bibliografia.

RESUMO: Os setores agrícola e têxtil, tềm sido os maiores alvos do protecionismo dos países desenvolvidos, que possuem em comum o fato de que a quantidade de mão-de-obra utilizada é bastante grande o que significa margem de variaçào do custo final do produto. Portanto, não é dificil entender porque os países quão mais subdesenvolvidos forem mais competitivos c ameaçadores são na disputa pelo controle do mercado mundial nestes setores. Assim decorre a importância da OMC, na busca pela efetividade da regulamentação do comércio internacional de bens agticolas é uma atividade que interessa aos países em desenvolvimento como um todo, o que é particularmente aplicável para o Brasil, onde os produtos agrícolas respondem por quase um terço das exportações.

ABSTRACT: The agricultural and textile sectors, have been the greaters targets of the developed countries protecionism, that possess in common

"Douromanda Universidade Federal de Santa Catarina Professona do Departanento de Direito da Universidade Federat de Satata Catarina - UFSC. antonilohomail.con 
the fact that the amount of man-power used is sufficiently great, it means a variation of the products" final cost. Therefore, it is not difficult to understand why the most underdeveloped countries are more competitive in the dispute of the world-wide market's control in these sectors. Thus the importance of the OMC elapses, in the search for the effectiveness of international trade regulation of agricultural goods is an activity that interests the developing countries, what is particularly applicable to Brazil, where the agricultutal products answers almost for one third of the exportations,

RESUMEN: Los sectores agrícolas y textil, han sido los mayores objetivos del proteccionismo de los países desarrollados, que poseen en común la cantidad de mano-de-obra usado y esta energia es suficientemente grande y significa variación del costo final del producto. Por tanto, tho es dificil comprender porque cuanto más subdesarrollados los países, más serán competitivos y amenazadores para el conflicto sobre el control del mercado mundial en estos sectores. Así la importancia del OMC transcurre, en la búsqueda para la eficacia de la regulación del comercio internacional de mercancias agricolas es una actividad que interesa a los países en vías de desarrollo en su totalidad, lo que es particularmente aplicable al Brasil, donde los productos agricolas casi contestan para un tercio de las exportaciones.

PALAVRAS-CHAVE: Comércio agrícola. Brasil. OMC. Exportações. Protecionismo. Acordo sobre Medidas Sanitátras e Fitossanitátias.

KEY-WORDS: Agricultural commerce. Brazil. OMC. Exportations. Protectionism. Agreement on Sanitary and Fitosanitary Measures.

PALABRAS-LLAVE: Comercio agrícola. El Brasil. OMC. Exportaciones. Proteccionismo. Acuerdo en las medidas Sanitarias y Fitosanitarias.

\section{Introdução}

O setor agrícola, bem como o setor têxtil, tem sido os maiores alvos do protecionismo adotado pelos países desenvolvidos, uma atitude contraditória à retórica adotada na sempre defesa pela liberalização do comércio mundial. Não é atoa. Estes setores têm em comum um dado fundamental que justifique tamanho cuidado: Em ambos a quantidade, mais do que a qualidade, de mão-de-obra empregada é enorme, o que, no 
mundo de hoje (e de sempre), significa margem de variação do custo final do produto. Assim, não é dificil entender porque os países quão mais sub-desenvolvidos forem mais competitivos e ameaçadores são na disputa pelo controle do mercado mundial nestes setores.

No caso do comércio agrícola, tema central deste ensaio, a discórdia encontra-se pautada em três grandes temas, quais sejam, subsídios às exportações ${ }^{1}$, acesso a mercados e medidas de apoio interno.

O comércio agrícola atinge aproximadamente $11 \%$ do comércio mundial de bens, representando cerca de US $\$ 580$ bilhões. Três quartos deste valor são representados por produtos alimentares. Do comércio total de bens agrícolas, os países em desenvolvimento têm participação de aproximadamente $29 \%{ }^{2}$

Para o Brasil, trata-se de setor fundamental para o desenvolvimento nacional. $\mathrm{O}$ agrobusiness corresponde a $32 \%$ do produto interno brasileiro (PIB), aproximadamente US $\$ 250$ bilhões anuais, e representa $38 \%$ da pauta de exportações, cerca de US $\$ 20$ bilhões anuais, abarcando $40 \%$ da população economicamente ativa do pais nesta atividade. Em 1997, por exemplo, o país foi o sexto maior exportador mundial de produtos agrícolas. ${ }^{3}$

Os EUA, sozinhos, detém 11\% mercado agrícola, ditando preços e comportamentos de mercado, o que, em verdade, apenas reflete a peculiar postura norte-americana e realismo político que rege a sua ações no campo das relaçôes internacionais. Os quinze países membros da união Européia respondem por $38 \%$ do mercado mundial agrícola. A agricultura é a grande preocupação da União Européia em seu processo de integração total, consumindo, a política agrícola, mais de $60 \%$ do PIB da Comunidade. $^{4}$

\footnotetext{
1 "Pode-se conceituar subsidio como sendo uma vantagen indevida, concedida pelo Estado, e que beneficia determinadas empresas ou setores. A condenação do subsidio fundamenta-se nas incorteções it que ele induz o mercado, impedindo uma melhor alocação de recursos e criando uma concorrència desleal. Embora tenha uma regulamentação próxima à do dumping, os subsidios são ocasionados por um ato estatal, enquato o dumping constitui uma prática privada de conquista de mercado. Entre 1979 e 1988 , os Estados Unidos iniciaram 371 aģes antisubsidios, contra 58 do resto dos páses do mundo. Dai Messerlin afirmar que para os Estados Unidos, o Código [do GATT] é um instrumento pata controlar subsidios. Para o resto do mundo, é um instrumento para controlat as medidas compensatórias americanas". BARRAL, Welber. Subsidios e Medidas Compensatórias na OMC, p. 371.

"Dados cm LUPL, André Lipp Basto. Comércio Agricola, in BARRAI, Welber (org). O Brasil e a OMC, os interesses brasileiros e as futuras negociaçoes multilaterais, Florianópolis: Diploma Legal, 2000, p. 185 ${ }^{3}$ Dados em CARVALHO, Leonardo A O futuro da agricultura, in BARRAL, Welber (org) O Barail e a OMC, p. 219 + Sobre as políticas da União Européia e seu processo de integração vide OLIVEIRA, Odete Maria de. União Eutopéia: Processos de integração e mutação, Curitiba: Juruá, 1999.
} 


\section{A Agricultura do GATT à OMC}

A discussão do setor agrícola nas disciplinas e normas do GATT (Acordo Geral de Tarifas e Comércio) deveria estar presente desde o início de sua criação, uma vez que este setor sempre foi considerado dos mais problemáticos pelos países desenvolvidos, iniciados os processos de descolonização. Contudo, devido as derrogações e exceções às obrigações do Acordo Geral, a fase de discussão sobre o setor só se deu a partir do Acordo de Blair House, entre Estados Unidos e Comunidade Européia, em 1992.

Este acordo teve papel fundamental no processo de liberalização do setor, não só por incluir na pauta de negociações o tema comércio agrícola, mas também, por reduziu os subsídios às exportações e os apoios domésticos aos produtores, convertendo as barreiras não tarifárias em tarifas equivalentes. Como resultado do projeto acordado em. Blair House, o Acordo sobre a Agricultura da Rodada Uruguay (AAG) consolidou e reduziu todas as tarifas, dando acesso às cotas mínimas para produtos que antes encontravam-se bloqueados por meio de medidas protecionistas. No entanto, não foi suficiente para os países em desenvolvimento, em especial para o Grupo de Cairns ${ }^{5}$, que esperava uma maior liberação do comércio agrícola.

A Rodada Uruguai findou por determinar uma maior liberalização, com gradualismo, na comercialização de produtos agrícolas, onde quotas foram substituidas por tarifas no âmbito do $A A G$, as quais deverão ser reduzidas em $36 \%$, até 2001 , nos países desenvolvidos, e em $24 \%$, até 2005 , nas economias em desenvolvimento.

Os compromissos específicos previstos para consolidação abarcam maior acesso a mercados, diminuição dos apoios domésticos e maior concorrência nas exportações, através da redução de subsídios à exportação. A negociação também incluiu um acordo sobre medidas sanitárias e fitossanitárias, para que tais medidas não se convertam em barreiras tarifárias.

\footnotetext{
O Grupo de Gaims representa um quarto das exportaçóes mundais de produtos agrícolas. Ele atualmente conta com quinze membros, quas sejam: Árica do Sul, Austrália, Argentina, Brasil, Canadá, Chile, Colòmbia, Fiji, Filipinas, Indonésia, Malásia, Nova Zelândia, Paraguai, Tailândia e Uruguai. G Gupo tem esse nome em razäo da cidade australiana de Cairns, onde se reuniram pela primeira vez $\mathrm{cm}$ 1986. O objetivo 6 a liberalização do setor nas pautas da OMC.

"Esses palses caracterizam-se por sercm, em sua grande maioriä, exportadores tradicionais de produtos primários, cujos custos relativos são inferiores à produção nas naçōes mais desenvolvidas, que por seu turno, apresentam mercados agricolas protegidos pelos mais variados mecanismos de retaliação comercial disponiveis, numa combinação de subsidios e pagamentos diretos ao produtor, internamente e restriçöes quantitativas c tarifarias, extemamente." CALOĖTE, Emanuel Malta Falcão. Agribusincss e economia brasleira, in BARRAL, Welber. O Brasil e a OMC, op. cit., p. 242. 
Estas regras e disciplinas devem garantir a importância da multifuncionalidade da agricultura e devem permitir uma fácil aplicação das políticas agrícolas internas, levando-se em conta as diferenças de condições naturais, e históricas de cada Membro. Os novos temas não pode ser deixados em segundo plano, o estabelecimento de um foro para discussão dos alimentos transgênicos é indispensável.

Contudo, os pontos abrangidos pelo AAG centraram-se, basicamente, na tríade postulada desde o início da Rodada: reduções nos subsídios às exportaçôes, aumento nas oportunidades de acesso a mercados e cortes nos subsídios à produção interna.

\section{Acesso a Mercados}

O plano para incrementar o acesso a mercados contém cinco elementos. São eles: a tarifação, a redução das tarifas vigentes e das resultantes da tarifação, a consolidação imediata de todas as tarifas referentes a produtos agrícolas, a salvaguarda especial e a cláusula de acesso mínimo.

Como o comércio agrícola estava repleto de medidas não tarifárias, o primeiro procedimento, em consonância com o principio da transparência vigente nos acordos da OMC seria transformar estas barreiras em medidas tarifárias a elas equivalentes (artigo 4 do AAG). Este processo ficou conhecido como tarifação (tarification).

"Também há um processo chamado de escalada tarifária, segundo o qual quanto mais processado for o produto maior será a tarifa aplicável. A escalada tarifária, chega em alguns casos a 17\% de diferença entre a tarifa aplicada ao produto primário e o processado, o que dificulta as iniciativas dos países em desenvolvimento de alcançar eficiência em suas indústrias de processamento de produtos agrícolas."

$O$ ponto fundamental deste tema para o Brasil centra-se na redução ao máximo das tarifas vigentes, usando como base para tanto os valores tarifários consolidados ao final do período de implementação do Acordo Agrícola.

São debatidos dentro deste grande tema os tópicos relacionados a tarifas', quotas, forma de aplicação de tarifas e salvaguardas especiais.

Grupo de Cairns propõe a ampliação considerável das oportunidades de acesso a mercados de todos os produtos agropecuários básicos bem como os elaborados, aplicando-se as mesmas condições dadas aos demais produtos.

"CI. LUPI, André Comercio agrícola, in BARRAI, Welber. O Brasil e a OMC, op. cit., p. 193. 
A União Européia é um grande exportador de produtos agrícolas e desejam participar da expansão do comércio mundial de produtos agropecuários.

O Governo Japonês, por sua vez, defende a tese de que os direitos tarifários são as únicas medidas de fronteira legítimas para ajustar as diferenças das condições naturais do países produtores agrícolas dentro do sistema da OMC. A tarificação deveria levar em conta o elementos como multifuncionalidade da agricultura e as condições reais de produção dos países.

\section{Subsídios às Exportações}

Tomando como base o período de 1986 a 1990, os desembolsos orçamentários anuais para subsídios às exportações devem ser reduzidos a 64\% do seu valor até o final do período de implementação, qual seja, seis anos a contar de $1^{\underline{a}}$ de janeiro de 1995 . No caso dos países em desenvolvimento o percentual a ser reduzido é de apenas $24 \%$, nos termos do artigo 9.2.b.iv do AAG.

O ponto central da proposta brasileira se relaciona aos subsídios à exportação e à eliminação dos mesmos, com vistas a liberalizar os mercados.

O Grupo de Cairns entende necessário a eliminação imediata, bem como a proibição, de todas as formas de subsídios à exportação e créditos à exportação, já que estas causam graves distúrbios no comércio internacional de produtos agrícolas.

Defendem os norte-americanos a eliminação absoluta dos subsídios às exportações, bem como de todas os subsídios à exportação definidas no Acordo sobre Agricultura.

Os EUA objetivam melhorar o acesso aos mercados uniformizando a estrutura tarifária dos membros da OMC, através do estabelecimento de listas, como as convencionadas nas negociações sobre a agricultura da Rodada Uruguai, onde todos o membros se comprometeram com a redução tarifária.

A UE está dispostas a continuar negociando a redução sempre que se apliquem a toda ajuda desse tipo critérios iguais. Também, deve-se cuidar de uma maneira satisfatória de outras formas menos transparentes de ajuda à exportação, em particular a intervenção de exportadores exclusivos e o ajuda alimentar na forma de créditos.

O Japão lembra que a demanda internacional de produtos agrícolas é inelástica e somente determinados países exportam esses produtos, que são importados por um número significativo de países. 
O comércio de exportação estatal japonês, que tem regras menos rígidas, evita os compromissos de redução de subsidios à exportação utilizando um sistema duplo de preços em função do destino das mercadorias exportadas.

\section{Medidas de Apoio Interno}

O apoio interno dado a agricultores europeus tem sido o ponto mais intrincado das negociações sobre a agricultura. Os incentivos dados pela União Européia aos seus produtores agrícolas compromete mais de $60 \%$ da renda da Comunidade, o que deixa evicente a importância do setor para os europeus.?

O AAG instituiu a Medida Agregada de Apoio (Aggregate Measure of Support - AMS), que é um indicador geral do nível de apoio interno concedido por cada Membro."

O Grupo de Cairns almeja um acordo entre os membros, objetivando reduzir significativamente a ajuda interna para todos os produtos agropecuários com a conseqüente eliminação de todas formas de subsídios intemos que distorcem o comércio, sendo permitido somente os que não geram este efeito

Contudo desejam a possibilidade de continuar com as políticas de ajuda interna que não distorçam o mercado agropecuário, como são as melhoras na infra-estrutura, na pesquisa e formação, além da ajuda na hipótese de catástrofes.

Os Norte-americanos assume uma postura bastante protecionista ao defender a tese de que os governos tem o direito de apoiar os agricultores se desejam fazê-lo, desde que esta ajuda não provoque alterações no mercado.

A União Européia pretende um compromisso geral onde todos os países adotem as medidas de redução tarifária, sugere um sistema de bandas tarifárias composto de três níveis, inferior, médio e superior, que poderia respeitar os níveis de desenvolvimento dos países.

Contudo, entende serem fundamentais as reformas nos instrumentos específicos do Acordo Agrícola, em particular as medidas de apoio "caixas verde e azul" que deve ser mantidas, além da manutenção da

\footnotetext{
"Maiores informaçoes vide Politica Comum Agrícola, em OLIVEIRA, Odete Maria de União Furopéa: Processos de integraça e matação, Curitiba: Juruá, 1999, p. 216 e seg.

"A reduça dos niveis de medidas globais de apoio interno (AMS) em $5 \%$ para ptoduça em pátes desenvolvidos $\mathrm{e} 10 \%$ para passes em desenvolvimento, tesultaria na reduça maior para os paises com maiores percentuais de AMS." CARVALHO, Leonardo. O futuro da agricultura, in BARRAL, Welber. O Brasil e a OMG op cit. p. 226.
} 
Cláusula de Paz com garantia de resultados para as próximas negociações. As questões não comerciais como segurança e qualidade alimentar, proteção ao meio ambientais, bem estar dos animais, também devem receber atenção especial, nas próximas discussões.

Para o Japão, a produção agrária produz bens de utilidade pública, como a multifuncionalidade tem demonstrado. A ajuda interna, portanto, dentro de certos níveis, é necessária e imprescindível para dar à agricultura sua função social.

\section{Acordo sobre Medidas Sanitárias c Fitossanitárias}

O Acordo sobre a Aplicação de Medidas Sanitárias e Fitossanitárias, no âmbito da OMC, procura assegurar que a preocupação com a saúde humana, animal e vegetal, não serão adotadas com vistas a criar proteções dissimuladas ao comércio internacional de alimentos.

O Artigo 2.2 do Acordo sobre a Aplicação de Medidas Sanitárias e Fitossanitárias estipula o seguinte: "Os membros assegurarão que qualquer medida sanitária e fitossanitária seja aplicada apenas na medida do necessário para proteger a vida ou a saúde humana, animal ou vegetal; seja baseada $\mathrm{em}$ princípios científicos e não seja mantida sem evidência científica suficiente."

\section{O Porquê da Abertura do Comércio}

A justificativa para uma maior liberalização de mercados baseia-se na observação de que o próprio processo de abertura favorece uma maior competição entre as firmas e faz com que o consumidor seja beneficiado pela expansão da oferta de produtos a preços mais baixos.

Os países da América Latina, via de regra, conviveram, nas décadas que antecederam a abertura comercial dos anos 90 , com o processo de substituição de importações. "No Brasil, vigorava a Lei do Similar Nacional (LSN) sob a qual, os empresários domésticos desfrutavam de amplos benefícios tanto financeiros quanto de garantias de mercado - concedidos pelo governo, para fabricar qualquer produto para o qual não houvesse, internamente, nenhuma firma concorrente." Inviabilizava-se a importação desses produtos, de modo a proteger esses empreendimentos nascentes.

\footnotetext{
"Informacoes en RASZL, Simone Moraes. Alimentos, in BARRAL, Welber. O Brasil e a OMC, op. dit, p. 270. in CALOETE, Emanuel Malta Falcão. Agribusiness e economia brasileira, in BARRAL, Welber. O Brasil e a $\mathrm{OMC}_{3}$ op. cit., p. 253. 
Esgotado o processo, questiona-se sobre os seus reais beneficios, já que em alguns setores não houve qualquer avanço significativo, às expensas da privação do acesso por parte dos consumidores aos produtos. $O$ governo destes países é o principal responsável, por não ter exigido, e continuar sem o fazer, uma contrapartida por parte das indústrias beneficiadas com a proteção, que seria o reinvestimento em capital humano e tecnologia no setor.

Assim, seguindo a tendência mundial, no início da década de 90 , a maior parte das tarifas de importação no Brasil foram reduzidas, sendo também revogada a Lei do Similar Nacional, permitindo-se maior acesso de produtos ao mercado doméstico.

Esse processo de abertura, se por um lado, permitiu uma maior modernização das firmas, reduzindo o preço de importação de matéria-prima, ajudando o controle interno de preços e sustentando a estabilidade, por outro, implicou maior endividamento externo e na reversão da tendência superavitária da balança comercial brasileira. ${ }^{11} \mathrm{O}$ processo de abertura de mercados fechados e restritos a tanto tempo deveria ter se dado de forma gradativa e não, como ocorreu, de uma só vez, inundando o mercado nacional com produtos estrangeiros e levando a bancarrota muitos dos produtores nacionais.

É fundamental que países procurem ingressar num sistema multilateral de comércio mais liberalizado, desde que sejam feitos, anteriormente, arranjos institucionais domésticos que sejam compatíveis com o aumento da capacidade produtiva nacional, da demanda interna e externa pelos produtos nos quais sejam endividadas as suas vantagens comparativas, perseguindose tal objetivo e a todo custo.

Portanto, a liberalização do comércio é, numa análise ideal, benéfica para todos, inclusive e principalmente para o consumidor. No sistema atual, os grandes beneficiários das altas tarifas, subsídios e barreiras não tarifárias são os produtores domésticos, que ganham, tanto pelo fato do preço interno do produto ser artificialmente mais elevado, quanto pelos pagamentos diretos feitos pelos governos para que restrinjam a sua produção.

Ganham também os produtores dos países menos desenvolvidos, que encontram nesses mercados preços maiores que os praticados no seu país de origem, de modo que, mesmo com a incidencia de pesados encargos, torna-se ainda vantajosa a comercializaçăo desses produtos.

\footnotetext{
1 "Verifica-se, recentemente, uma maior concentração do processo de comercializaçâo no Brasil. Com as incorporaços e fusöes de empresas nacionats por grandes firmas estrangeiras do setor, observase a tendência de descaracterizaçäo da formaça de preços em termos concorrenciais. Atualmente, 17 empresas multinacionais, representando apenas $0,30 \%$ do número de empresas exportadoras agrícolas, controlam $43 \%$ das exportaçoes brasileiras de commodities agricolas, enquanto 4 mil empresas (70\% do universo), rcspondem por apenas $1 \%$ das exportaçố agricolas." CALOÊTE, Emanual Malta Falcão. Agribusiness e economia brasileira, in BARRAL, Welber. O Brasil e a OMC, op. cit, p. 254.
} 
Perdem os consumidores dos países que praticam o subsidio e também todos os agentes econômicos globalmente, pois o ganho de bemestar dos produtores é muito menor que a perda dos consumidores, sob qualquer aspecto. Os produtores dos países mais desenvolvidos são, portanto, os beneficiados pela proteção e não têm interesse algum no livre comercio. $^{12}$

O comércio agrícola, tal como hoje praticado, é um exemplo efetivo de tratamento especial e diferenciado na OMC. Beneficia, infelizmente, apenas aqueles que não necessitariam privilégios. $O$ Brasil pretende, para os produtos que exporta, as mesmas condições de acesso a mercado e as mesmas disciplinas que os paises desenvolvidos se habituaram a esperar em suas exportações para nosso mercado.

\section{Conclusão}

É nítido que, independentemente das consideraçôes acerca das vantagens ou desvantagens do comércio multilateral liberalizado, não há "bem intencionados" no mercado darwiniano ${ }^{13}$ que caracteriza as relações internacionais comerciais. Assim, toda a análise e conclusões sobre a liberalização do comércio será parcial, a medida que se limitar a enfocar apenas um dos inúmeros aspectos que a compõem, como o econômico, político, social, humano.

De todo modo, mesmo incipientemente, é possível traçar algumas considerações finais sobre o tema, que podem ser resumidas numa frase: A regra do comércio livre em igualdade de condições não vale para o setor agrícola dos países em desenvolvimento. Isto porque, como visto, os ganhos dos produtores dos países desenvolvidos são muito elevados, em detrimento dos consumidores.

O protecionismo apresenta tendências crescentes nos países desenvolvidos. A todo momento, preocupações legitimas e a boa fé das pessoas são usados como disfarces. Padröes ambientais e trabalhistas, a sempre retórica de proteção aos direitos humanos e sociais, são exemplos de temas importados para a agenda internacional do comércio, e para o âmbito da OMC, como mecanismos de controle e proteção do mercado, bem como sua manutenção no status quo.

\footnotetext{
${ }^{12}$ A respeito das teorias do comércio intemacional e seus fatores, numa análise economica das perdas e gunhos com o cométcio internacional, vide: SYKES, Alan. Regulatory protectionism and the law of internacional trade. The University of Chicugo Law Review, Chicago: v.66, n.1, winter 1999; TREBILCOCK, Michael \& HOWSE, Robert. The regulation of internacional trade, $2^{2} \mathrm{ed}$, London: Routners, $1999 \mathrm{e}$ BARRAL, Welber \& REIS, Geraldo Antônio dos. Globalização e o novo marco regulatório do cométcio internacional: a inserço brasileira, Ensaios FEE, Porto Alegre: v.20, n.1, 1999.

${ }^{3}$ Darwin foi o criador da Teoria da Seleção Natural. cuja máxima estáa representada pela força e adaptabilidade ao meio. "Só os mais fortes e aptos sobrevivem". 
Impressionantemente, num mundo onde todos são produtores intensos de alimentos brigando violentamente por sua quota no mercado internacional, existem hoje e ainda 800 milhões de pessoas famintas no mundo, segundo dados da FAO. A distribuição de alimentos, mais do que sua produção, controle e comércio, deveria encabeçar a pauta de discussão e as preocupaçōes dos países ao se reunirem para tratar da agricultura. (...)

Anyway, se nome do jogo é livre comércio, ainda há muito a fazer para aperfeiçoar suas regras. $O$ mundo real não oferece igualdade de condiçōes para todos no mercado internacional como este se apresenta. A criação de mecanismos que evitem a submissão dos fracos aos fortes faz-se urgente e imprescindivel num mercado internacional onde vigoram, atualmente, dois pesos e duas medidas.

A busca pela efetividade da regulamentação do comércio internacional de bens agrícolas é uma atividade que interessa aos países em desenvolvimento como um todo, pois é através das exportações destes bens que eles adquirem condições de importar tecnologia e manter suas balanças de pagamentos. Isto é particularmente aplicável para o Brasil, onde os produtos agrícolas respondem por quase um terço das exportações.

Finalmente, é preciso que as políticas agrárias internas sejam reformadas, com maior investimento em pesquisa e tecnologia, com a modificação no sistema de tributação e com a realização da reforma agrária, cujas vantagens sociais já por si só a recomendam. Em se tratando de alimentos, ignorar o fator humano e social no mundo de hoje é, além de estúpido, economicamente desvantajoso.

\section{BIBLIOGRAFIA}

BARRAL, Welber \& REIS, Geraldo Antônio dos. Globalização e o novo marco regulatório do comércio internacional: a inserção brasileira, Ensaios FEE, Porto Alegre: v.20, n.1, 1999.

BARRAL, Welber. Subsídios e Medidas Compensatórias na OMC, (texto sem referência bibliográfica), s.l, s.d.

CALOETE, Emanuel Malta Falcão. Agribusiness e economia brasileira, in BARRAL, Welber. O Brasil e a OMC, os interesses brasileiros e as futuras negociações multilaterais, Florianópolis: Diploma Legal, 2000.

CARVALHO, Leonardo A. O futuro da agricultura, in BARRAL, Welber (org). O Brasil e a $\mathrm{OMC}$, os interesses brasileiros e as futuras negociações multilaterais, Florianópolis: Diploma Legal, 2000. 
LUPI, André Lipp Basto. Comércio Agrícola, in BARRAL, Welber (org). O Brasil e a OMC, os interesses brasileiros e as futuras negociaçóes multilaterais, Florianópolis: Diploma Legal, 2000.

OLIVEIRA, Odete Maria de. União Européia: Processos de integração e mutação, Curitiba: Juruá, 1999.

RASZL, Simone Moraes. Alimentos, in BARRAL, Welber. O Brasil e a OMC, os interesses brasileiros e as futuras negociaçoes multilaterais, Florianópolis: Diploma Legal, 2000.

SYKES, Alan. Regulatory protectionism and the law of internacional trade. The University of Chicago Law Review, Chicago: v.66, n.1, winter 1999. TREBILCOCK, Michael \& HOWSE, Robert. The regulation of internacional trade, $2^{\circ}$ ed., London: Routners, 1999. 